\title{
Erratum to: Phylogeny and biogeography of the genus Stevia (Asteraceae: Eupatorieae): an example of diversification in the Asteraceae in the new world
}

\author{
Akiko Soejima ${ }^{1}$ - Akifumi S. Tanabe ${ }^{2}$ Izumi Takayama ${ }^{3}$ ' Takayuki Kawahara ${ }^{4}$.

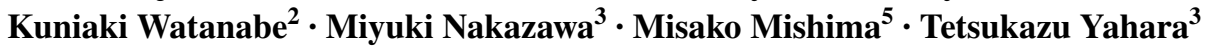

Published online: 17 July 2017

(C) The Botanical Society of Japan and Springer Japan KK 2017

\section{Erratum to: J Plant Res}

\section{DOI 10.1007/s10265-017-0955-z}

In original publication of the article, some information in Table 1 is incorrect. The errors are corrected in this erratum.

1. The chromosome number of $S$. mitopoda (Y1022) should be changed from $2 n-24$ to $2 n=24$.

2. The chromosome number of S. nepetifolia (Y0857) should be changed from $2 \mathrm{n}=36$ to $2 \mathrm{n}=33+0 \sim 3 \mathrm{~B}$.
The online version of the original article can be found under doi:10.1007/s10265-017-0955-z.

Akiko Soejima

soejima@sci.kumamoto-u.ac.jp

1 Department of Biological Science, Faculty of Advanced Science and Technology, Kumamoto University, Kumamoto 860-8555, Japan

2 Department of Biology, Graduate School of Science, Kobe University, Kobe 657-8501, Japan

3 Department of Biology, Graduate School of Science, Kyushu University, Fukuoka 819-0395, Japan

4 Hokkaido Research Center Forestry and Forest Products Research Institute, Sapporo 062-8516, Japan

5 University Museum, Kyushu University, Fukuoka 812-8581, Japan
3. The chromosome number of S. nepetifolia (Y0983) should be changed from $2 n=48$ to $2 n=44+0 \sim 4 B$.

4. The species name of $S$. seemanioides should be replaced with $S$. seemannioides, and the rows of $S$. seemannioides and S. seemannii should be transposed. 